Document downloaded from:

http://hdl.handle.net/10251/54169

This paper must be cited as:

Maheut, JPD.; Besga, JM.; Uribetsebarria, J.; García Sabater, JP. (2014). A decision support system for modelling and implementing the supply network configuration and operations scheduling problem in the machine tool industry. Production Planning and Control. 25(8):679-697. doi:10.1080/09537287.2013.798087.

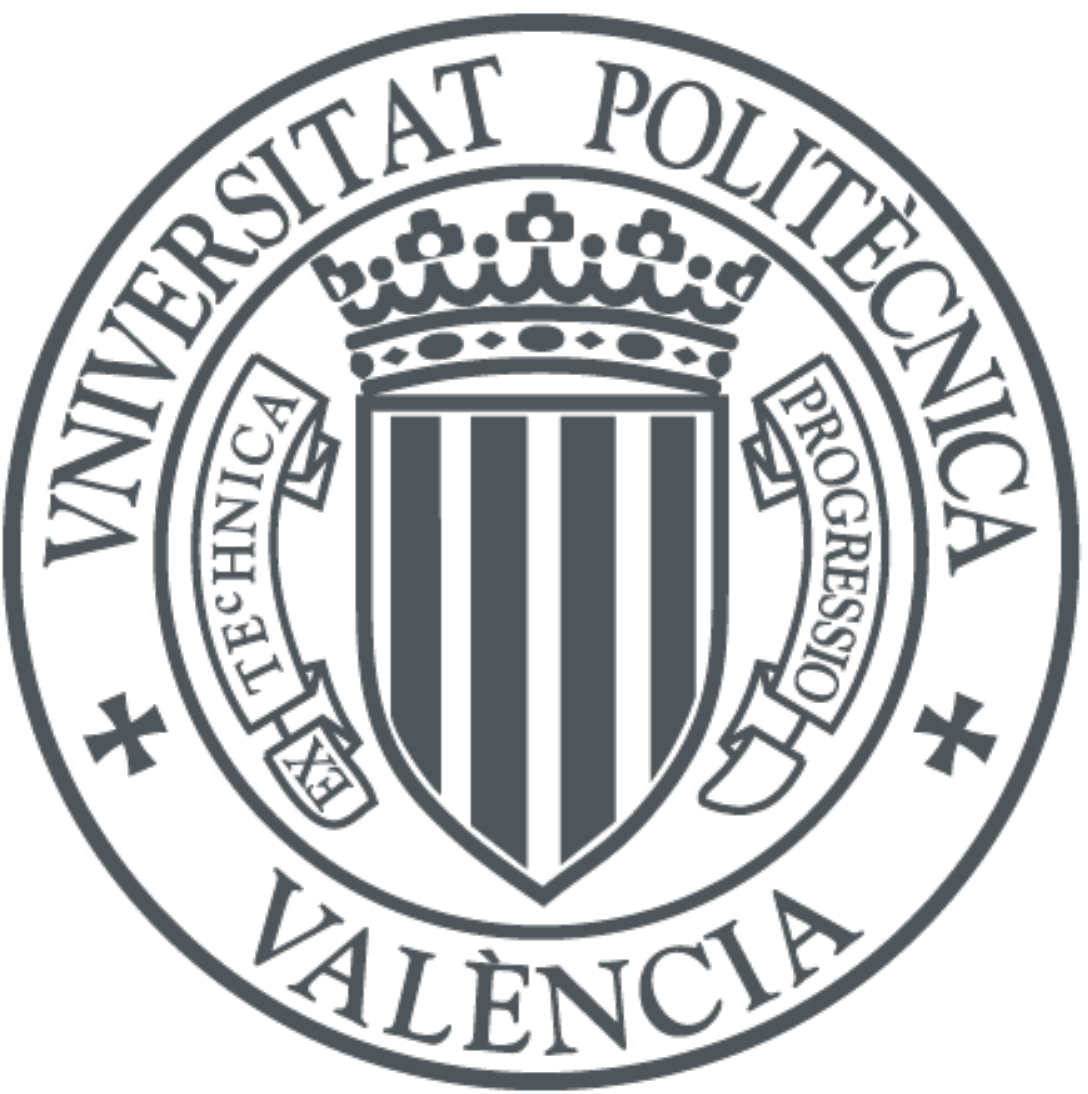

The final publication is available at

http://dx.doi.org/10.1080/09537287.2013.798087

Copyright Taylor \& Francis

Additional Information 


\title{
A Decision Support System for modeling and implementing the Supply Network Configuration and Operations Scheduling problem in the machine tool industry
}

\author{
Julien Maheut ${ }^{\mathrm{a} *}$, Juan Manuel Besga ${ }^{\mathrm{b}}$, Jone Uribetxeberria ${ }^{\mathrm{b}}$,Jose P. Garcia- \\ Sabater $^{\mathrm{a}}$
}

${ }^{a}$ Departamento de Organización de Empresas, Universitat Politecnica de Valencia, Valencia, Spain

${ }^{b}$ IKERLAN Technological Research Center, Arrasate-Mondragón, Spain

Corresponding author. Email: juma2@upv.es

This paper presents a decision support system to simultaneously solve the supply network configuration problem and the operations scheduling problem for the machine tool industry. A novel database structure, which is able to consider alternative operations and alternative bills of material, has been used. An algorithm for complete enumeration to determine all the feasible solutions using stroke graphs is introduced. A multiagent-based simulator evaluates the different key performance indicators that the supply network deals with for each alternative solution (e.g., workload, profits, delivery times, etc.) to determine that "satisficed" by the collaborative decision making among its members. A case study based on a Spanish company that assembles highly customized machines and tools in several European plants is considered. From the experiments results based on data linked to this industry it will be demonstrated that the tool is potentially useful for stakeholders and for the central decision maker to make decisions collaboratively in a multisite context case.

Keywords: Supply Network Configuration; Decision Support System; Mass Customization; Simulation; Collaborative operations planning

\section{Introduction}

Supply chains compete, and have to differentiate among, competitors and other supply chains in an increasingly globalized world, and they are always seeking to reduce costs and to obtain minimum delivery times by meeting or exceeding customer 
expectations and by offering high levels of quality and/or services (Christopher, 1998, Mula et al., 2012). For capital goods companies, such as manufacturers of civil engineering and construction machinery, plastic injection machinery or machine tools, the highly competitive environment means that companies are obliged to offer increasingly personalized products to end customers (Saiz et al., 2012). This customization entails offering customers an extensive product catalogue, renewing it regularly and assuming the complexity of managing a product inventory with increasingly shorter life cycles (Da Silveira et al., 2001). Product diversity, increased complexity in operations processes and higher costs of materials are critical management keys that need to be considered in order to remain competitive (Tynjälä and Eloranta, 2007).

The key question that planners often ask is: how can my supply chain or my supply network (SN) serve the desired products to my customers and meet their expectations while also minimizing total logistics costs, assuming short delivery times and ensuring levelled workloads in the various production centres to be able to respond to future orders? This question is fundamental for companies that assemble machine tools because orders are not regular, but specific. Given the frequency of orders, the cost of electronic components and raw materials, customer locations or the variety of options offered, it can be demonstrated that a solution attempting to optimize only the cost or delivery date of each order separately is unsuitable. A better solution considers more indicators to help make a decision that "satisfices" the majority of stakeholders (Guinery and MacCarthy, 2009).

Moreover, resources (workforce, machinery, space, etc.) planning is a concern that must not be treated in an isolated manner because it often has a marked effect on operation scheduling activities (Maheut et al., 2012). For instance, frequently two plants 
in two different countries are able to manufacture the same product with different costs and constraints (Garcia-Sabater et al., 2013). When operations planning has to be done in a multisite context and there is a different way to respond to demand, the SN problem can contemplate several feasible configurations (Graves and Willems, 2005). By way of example, raw materials can be purchased from different suppliers (Aissaoui et al., 2007), products can be produced or assembled on different machines or in different plants, or products can be delivered/transported by different modes of transport ( Chaabane et al., 2011). Selecting a configuration implies reaching a compromise among the profits/costs involved, the service levels offered to customers and plant workload levelling by collaborative decision making.

Integrating the supply network configuration (SNC) problem and the operations scheduling problem to be performed into a multisite context in the machine tool industry is required not only to optimize the $\mathrm{SN}$ at any given time, but also to anticipate new orders. To answer these questions, a decision support system (DSS) often proves useful because it is based on a set of procedures supported by models for the data processing of unstructured problems (Power and Sharda, 2009).

The following section briefly reviews the literature about collaborative planning, DSSs for supply network configuration and operations scheduling in industry. Section 3 describes an $\mathrm{SN}$ for the manufacturing of milling machines. Section 4 presents the proposed DSS, its database architecture, the algorithm for complete enumeration and the simulation module. Section 5 offers an experiment results analysis and some managerial implications. Finally, Section 6 provides conclusions and future research lines.

\section{Brief literature review}

Collaborative planning requires individual plans to be adapted in joint decision- 
making efforts, as defined by Stadtler (2009). In this work, Stadtler provides a framework and an overview on state-of-the-art collaborative planning. Hernández et al. (2009) presents the most updated review of the relevant literature in existing agentbased modelling methodologies that support collaborative supply chain planning.

In general, and unlike Advanced Planning \& Scheduling Systems (Stadtler, 2005), DSSs are designed specifically for a particular industry. The literature contains many references where DSSs have been designed and implemented in specific industry cases. To help present our contribution, some DSSs proposing some similar interesting aspects developed in our tool are reviewed.

Respicio et al. (2002) present a case study that describes a DSS for production planning and scheduling in a paper industry company. In this tool, submodels are coordinated with a hierarchical mechanism. Cowling (2003) reports a DSS for steel hot rolling mill scheduling. In this system, a Tabu Search metaheuristic is used to solve a multiobjective problem where objectives may come into conflict with the manner of satisfying some restrictions. Farrell and Maness (2005) propose a DSS for secondary wood product planning based on linear programming models. Their main contribution is based on the use of a relational database that enables the generation of feasible models depending on user inputs. Gomes da Silva et al. (2006) put forward a DSS which uses a multicriterion MILP model to solve the aggregate production planning problems of a Portuguese company in the construction sector. The authors propose the use of a DSS and an interesting methodology where stakeholders can modify models so that the results are in line with reality and where those scenarios which enable a "what if?" analysis can be generated.

However to the best of our knowledge, a DSS capable of simultaneously solving the SNC problem and the alternative operations scheduling problem in a machine tool 
SN that supports collaborative decision making has not yet been proposed. As this is the aim of this paper, its main contributions are summarized below:

- A DSS to solve the SNC problem and the operations scheduling problem for the machine tool industry that assembles highly customized products in several plants.

- A novel database structure capable of considering alternative operations (purchasing, production, transportation) and alternative BOMs (upgrading, reconfiguring custom products).

- An algorithm based on a direct hypergraph for complete enumeration to determine all the feasible solutions.

- A multiagent-based simulator to evaluate the value of the different key performance indicators (KPIs) for each alternative solution.

\section{Supply network description of the milling machine manufacturing industry}

\subsection{Product structure and customers}

Milling machines are apparatus with a complex structure made up of thousands of different components. These components are grouped into functional units (Figure 1) that respond to a set of customer attributes. An attribute can be fixed or can belong to a range of values called options.

The main customers of these products come from very diverse sectors as follows: aerospace, capital goods, railways, subcontractors, or mould and die manufacturers. An extensive catalogue including several families according to machine size, bed type and column type is offered to customers. Customers configure their order 
by selecting the best option for each attribute; thus, a combinatorial problem is generated.

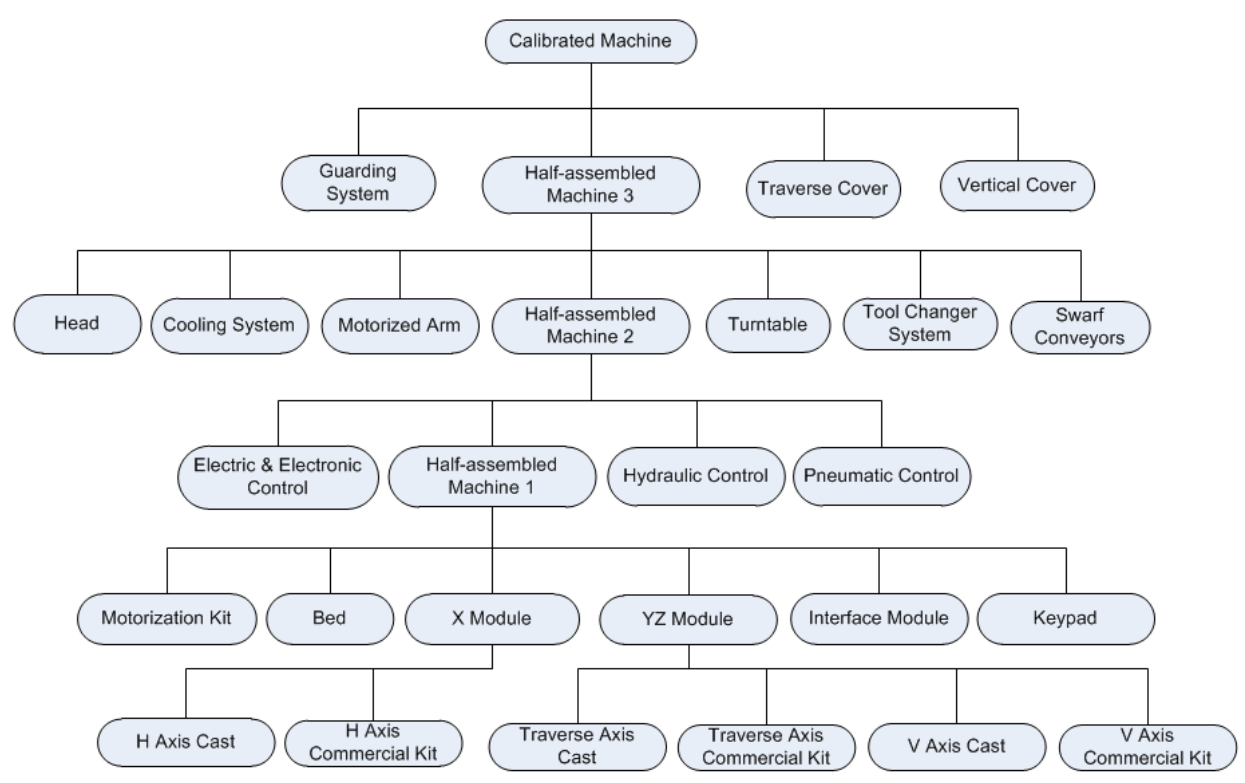

Figure 1. Structure of the milling machine

The variety of end products in the milling machine sector has increased in recent decades. Nowadays, the number of product variants theoretically includes around 2.5 billion possible combinations (Saiz et al., 2009). Moreover, increasing market pressure on the $\mathrm{SN}$ is continuously detected. One example is what has happened with small milling machines in some specific cases: the market demands delivery times of about 14 weeks for urgent orders, which is clearly shorter than the 30 weeks needed to buy all the components and assemble them, and to transport the end product to the customer.

\subsection{Manufacturing processes}

The delivery time given for any milling machine includes planning tasks, launch and manufacturing activities for the machines, as well as transport activities and installation in the customer's plant. The first step consists of the order planning stage, which starts when a new order arrives. Basically, it consists of determining the characteristics of the machine to be manufactured and where it is to be manufactured. 
The planning task not only includes the SNC, but determines the scheduling of the different operations to be performed by considering all the feasible alternative solutions in terms of alternative BOMs (Ram et al., 2006, Garcia-Sabater et al., 2012). Components are received during practically the whole machine assembly process. The procurement time depends on the suppliers' location and on the component.

The initial machine assembly includes preliminary mechanical assembly operations, and the assembly of pneumatic, hydraulic and electric groups and components.

Having completed the initial assembly, two situations can arise: If the order is build-to-forecast and the product has not been allocated, it is placed in stock (Case 1); The product moves to the final assembly stage to carry out the machine (re)configuration operations by adapting it to customer order requirements, the fine tuning of the electronics and mechanical parts, shrouding installation, in-plant testing, machine painting and customer reception (Case 2). Finally, the machine is dispatched and taken to the specified place by the customer, where it is installed. This stage requires between 1 and 2 weeks.

\section{The REMPLANET DSS tool}

REMPLANET DSS is a tool for collaborative decision making that offers a solution to a series of problems identified in the machines-tools sector: the supply network design with a new site location; establishing the position of inventories and replenishment policies; the identification and position of the customer order type decoupling point; the SN configuration problem and operations scheduling for a given SN (Saiz et al., 2012). This tool has been designed in REMPLANET, a collaborative project funded by the European Commission Seventh Framework Programme; more details can be obtained at www.remplanet.eu. 
For many scenarios and conditions, this tool not only conducts the systematic testing of the structure and operation of this type of complex SNs, along with their behavioural patterns and properties, but also identifies alternative flexible SN structures, and those strategies, policies and rules that better suit their management, at both the local and global network levels, at low cost and with very little risk. However, given the scope of this paper, only the most interesting features related with the SN configuration problem and operations scheduling for a given $\mathrm{SN}$ issue are dealt with. The tool contains four basic components: (1) a relational database capable of considering alternative operations, (2) the collaborative process, (3) an algorithm for complete enumeration, (4) an agent-based simulation model with the agent definitions and (5) a graphical user interface. The five components are described below.

\subsection{Database}

Each product is represented as a stock keeping unit (SKU), a localized product (Baptiste et al., 2008). All the operations are represented using the stroke concept (Garcia-Sabater et al., 2013): a stroke represents any localized operation that transforms (or transports) a set of SKUs into another set of SKUs. This localized operation, and therefore the stroke representing it, has associated characteristics (stroke cost, lead time, setup stroke cost, etc.) and consumes a certain amount of resources (see Figure 2). As SKUs must consider the site where they are stored, a specific nomenclature has been designed. For example, product "P01" stored in plant "A" is called "P01 @ A". One unit of SKU "P01@A" is obtained when one unit of "Stroke Stk01" is performed. When this stroke is performed, one unit of "P02@A" and "P04@A" and two units of "P03@ A" are consumed. 


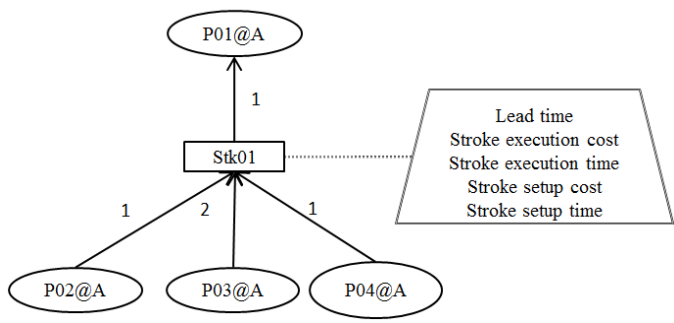

Figure 2. Example of a conceptual representation of one stroke

The DSS relational database comprises tens of tables. However, in order to emphasize our contribution, this section presents only those tables required to consider alternative operations and alternative BOMs (see Figure 3).

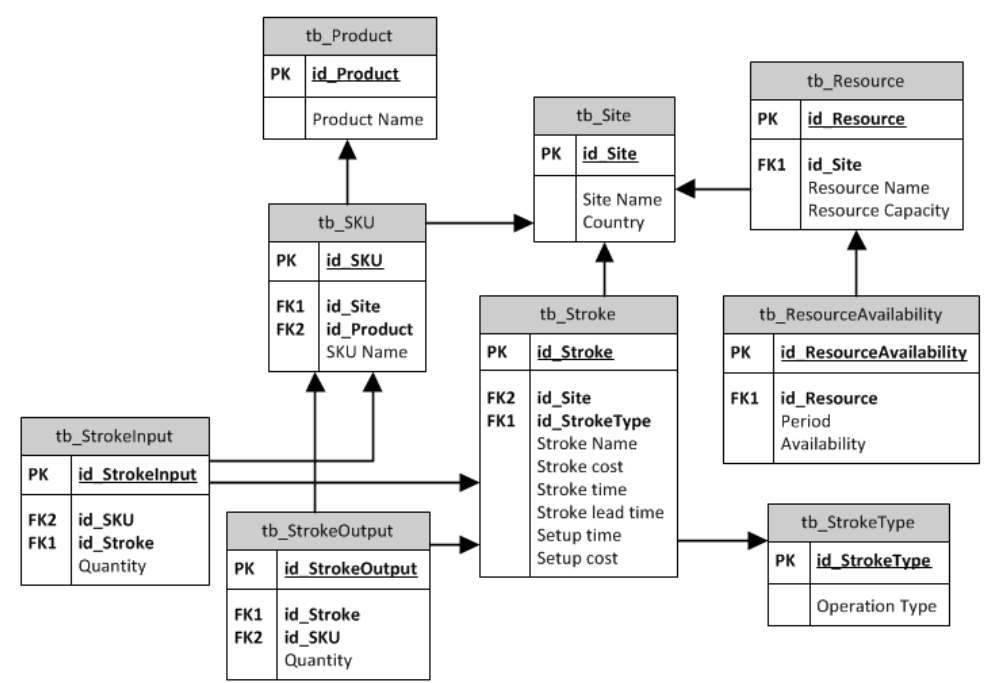

Figure 3. The architecture of the relational database

Nine tables are required to consider alternative operations (see Figure 3). Each relational database table is explained in Table 1. Unlike traditional BOMs based on a parent item table, with a child item table and the so-called in-going parts of the parent item in (Aydin and Güngör, 2005), our database structure proposes a list of the operations (called strokes) that must be incorporated between two tables listing SKUs' consumption and SKUs' generation.

Table 1. Description of the relational database tables 


\begin{tabular}{|c|c|}
\hline Table name & Description \\
\hline tb_Site & > Lists data about each plant, supplier, and customer of the SN. Each site is unique. \\
\hline tb_Product & $\begin{array}{l}\text { > Lists all products considered in the SN. } \\
\text { > Describes all the data related to a product, item or packaging. }\end{array}$ \\
\hline tb_SKU & $\begin{array}{l}>\text { Lists all stock keeping units (SKUs) which are localized products in its corresponding packaging. A product } \\
\text { presented in two different sites or packaging is represented with two distinct and unique SKUs. } \\
>\text { Generates with tb_Sites and tb_Product. }\end{array}$ \\
\hline tb_Resource & $\begin{array}{l}\text { > Lists all localized resources. } \\
>\text { Localized resources are machineries, workforce resources or any resource that have to be planned and with an } \\
\text { available capacity. }\end{array}$ \\
\hline tb_StrokeType & $\begin{array}{l}\text { > Lists the different operations types that must be considered. } \\
>\text { Operations types considered are assembly, procurement, selection, transport. }\end{array}$ \\
\hline tb_Stroke & $\begin{array}{l}>\text { Lists all localized operations. } \\
>\text { Each stroke has a unique identifier, location, and type. } \\
>\text { Stores data about the immobilized resources when one unit of stroke is performed (in terms of cost and time). }\end{array}$ \\
\hline tb_StrokeOutput & $\begin{array}{l}\text { > Lists the associated SKUs which are generated when one unit of stroke is performed. } \\
>\text { The quantity of SKUs generated is a crucial data in case of lotsizing. }\end{array}$ \\
\hline tb_Strokelnput & $\begin{array}{l}\text { > Lists the associated SKUs which are consumed when one unit of stroke is performed. } \\
\text { > The quantity of SKUs generated is a crucial data in case of lotsizing. }\end{array}$ \\
\hline
\end{tabular}

Traditionally, in order to consider alternative BOMs, a table with substitutes is associated with each parent item table or child item table. Similarly, the consideration of alternative resources is made with another table, and co-products or by-products can be contemplated with other tables. In order to avoid the deficiency of using multiple tables and of considering alternatives at the same time, Garcia-Sabater et al. (2013) demonstrate that the use of the stroke concept is a compact way of representing alternative operations. Moreover, this relational database (see Figure 3) proposes the architecture to structure data in order to consider alternatives, which may occur in industry, as Maheut and Garcia-Sabater evidence (2011).

\subsection{The collaborative process}

As stated by Hernández et al. (2009), a complete description of the collaborative process must consider, among others, the interaction criteria and the coordination mechanism. The interaction criteria are described in section 5 .

The coordination mechanism starts when each SN member imports its BOMs onto a website. To collaborate in the planning process, each member must manually enter new strokes to consider alternatives. In this stage, the stroke types contemplated are procurement, transformation and transport. Selection strokes are the strokes created automatically by the procedure for complete enumeration. 
When a new order arrives, the web-based tool collects all the tables of each member and builds a centralized database instance. However, various data problems usually arise: members do not consider transport between plants; some purchase transactions are not contemplated; the difficulty of assessing or contemplating alternatives that have not been considered before; or reconfiguration and upgrading operations do not exist by definition in the traditional information systems. To overcome these data problems, different mechanisms to check them are implemented to ensure their integrity, two of which are described below:

- A data mechanism checks that each SKU consumed in the set of strokes has the output of at least one stroke of the same location. If no stroke consuming the SKU exists in the same location, and if a stroke in another location generates the SKU, the generation of a new transportation stroke is offered to members. If no stroke generates the SKU, it is proposed to the planner of the location to introduce a new purchase stroke or to modify its data.

- If some non-allocated SKUs are in stock and belong to the same family or have similar attributes to some components in the order, another mechanism proposes the introduction of a reconfiguration stroke with its associated costs and times.

In this way, different mechanisms ensure that each SKU can be transformed or bought in the different plants. Moreover, the system has been designed to suggest users the following: consideration of transport operations that did not exist in their information systems; inclusion of transport alternatives; simultaneous consideration of assembly operations and disassembly operations. The need to have reliable data and the effect of a simulation containing incomplete date create the need for sharing information among the various actors of the SN for the purpose of improving the behaviour of the tool. 


\subsection{Algorithm for complete enumeration}

As previously mentioned, once the database has been completed and integrated into the central decision-making tool, the end product ordered by the customer can be achieved in at least one way and a stroke graph can be represented (see Figure 4).

However, the existence of alternatives in the $\mathrm{SN}$ and the needs to evaluate and assess each feasible and practical solution justify the need to offer stakeholders and the central decision maker the complete enumeration of all the possibilities to configure the SN and to schedule operations. The complete algorithm description is presented in (Maheut and Garcia-Sabater, 2013).

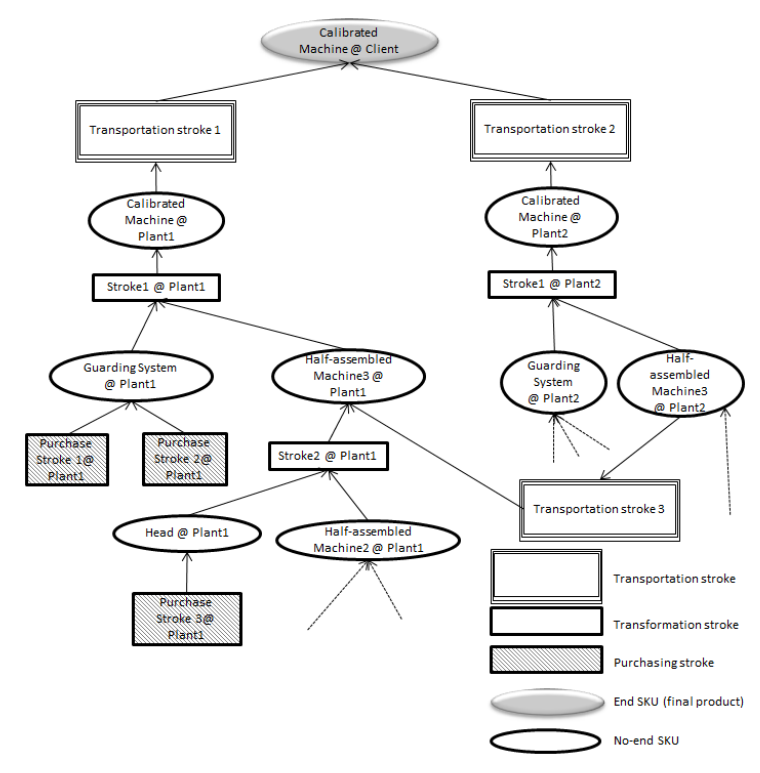

Figure 4. Example of a partial stroke graph

As depicted in Figure 4, the Calibrated Machine can be assembled completely in "Plant1", completely in "Plant2" or the assembly of "Half-assembled Machine3" can be performed in "Plant2" and sent to "Plant1" ("Transportation stroke 3"), where final activities are carried out. Finally, the finished machine is sent to the customer from "Plant1" (“Transportation stroke 1") or "Plant2" (“Transportation stroke 2"), depending on the plant that has finished the machine. 
As the same SKU can be generated by different operations and the theoretical combination number can be important, a procedure based on complete enumeration has been developed and implemented. The procedure consists in the following steps to avoid generating repetitive/similar solutions:

1. Transformation of the relational database into a hybrid hypergraph. The relational database enables alternative operations to be generated for the order to be transformed into a hybrid database. The aim of this step is to determine where the alternatives are; that is, the SKUs that can be generated by 2 or more strokes (see Figure 5). For each alternative, a selection stroke and the corresponding phantom SKU are created and stored in the database. In Figure 5, the selection strokes and phantom SKUs have been introduced for the following SKUs: “Calibrated Machine@Client”, “Guarding System @Plant1” and "Half-assembled Machine3@Plant1”.

2. Creation of the AND-XOR hypergraph. In this step, an AND-XOR hypergraph is created from the hybrid database. Strokes and SKU are transformed into nodes and arcs (see Figure 6). Each SKU is transformed into a node, and each stroke is transformed into an arc.

3. Generation of all the feasible solutions. All the feasible solutions are generated by binary arc and node vectors. An algorithm based on the complete enumeration of vectors is used. 

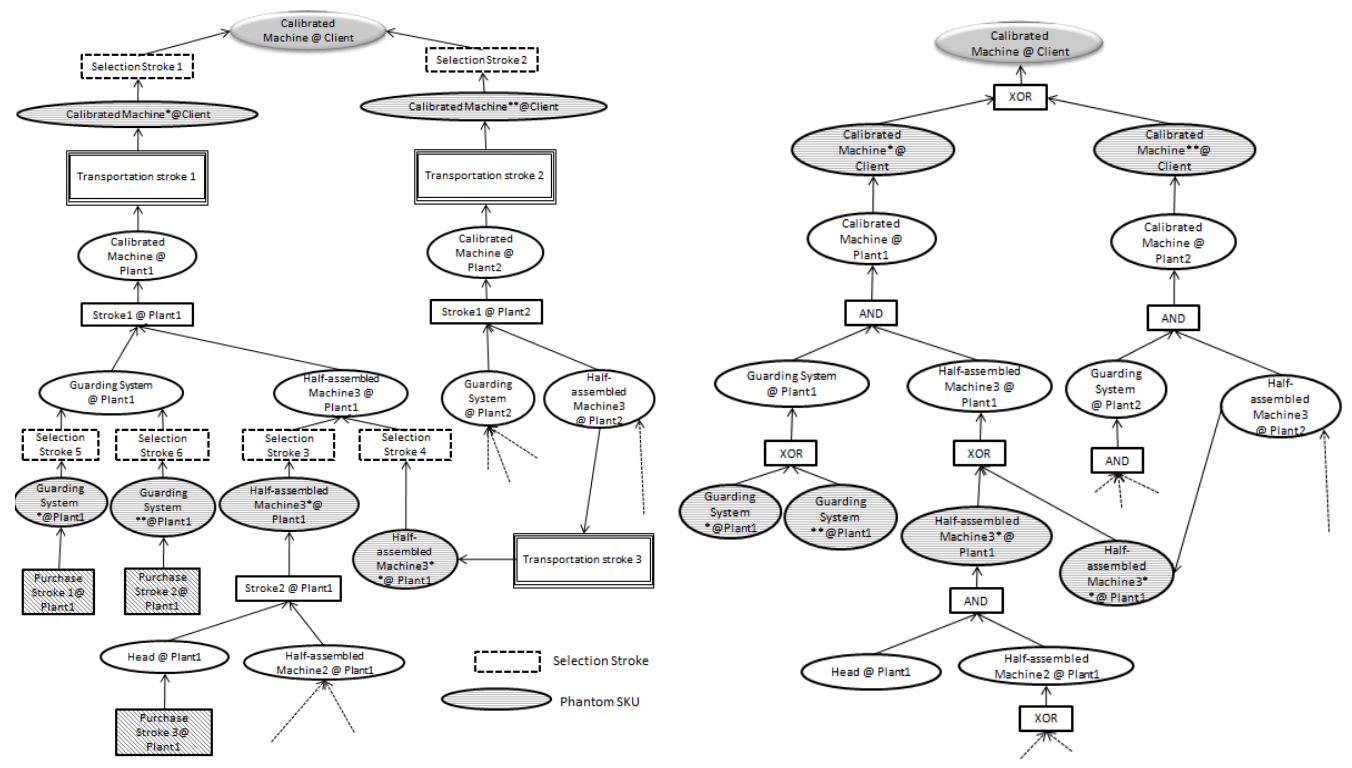

Figure 5. Hybrid hypergraph

Figure 6. AND-XOR hypergraph

4. Calculation of each solution KPI. For each feasible hypergraph solution, the strokes that must be performed are determined from their active arcs in the hypergraph. The solution is evaluated in the DSS simulator and the corresponding KPIs are calculated.

5. Selection of solutions. Should the quantity of feasible solutions be large, a selection mechanism has been developed to help the central decision maker to select those solutions with an interesting ratio between profits and delivery times. For instance, those solutions that do not respect delivery times or imply excessively high costs are eliminated. However, stakeholders can define other criteria to eliminate those solutions that do not suit them.

\subsection{The DSS simulator}

This simulator has been developed with the Anylogic simulation software ${ }^{\circledR}$. AnyLogic is a forward-looking simulation software which uses an object-oriented approach, a Unified Modelling Language (UML) visual notation, supports agent-based modelling, as well as other modelling approaches, and it provides a rich animation of 
model execution and handles randomness (Karpov et al., 2005). A complete description of the simulation tool can be found at www.anylogic.com. The simulation methodology used in the DSS is mainly agent-based modelling, but discrete-event modelling has also been utilized.

The different types of agents implemented are presented below:

- Supply chain agent: it contains the agents' network and records the indicators of response in the structure of the KPIs.

- Market agent: it characterizes the order type.

- Point sales agent: it creates product orders following the rules defined in the market.

- Coordinator agent: it decides when and how to respond to a customer order, supervises the execution of orders from the reception to the delivery of the product to the customer, and updates the strategy indicators defined in the structure of the KPIs.

- Customer order agent: it is an internal agent of the coordinator agent which executes the order and supervises how the customer order develops.

- Plant node agent: it is a network node (suppliers, assemblers, manufacturers, warehouses) that produces the customized product for each customer order. It receives orders from the coordinator agent.

- Items agent: it simulates the operation of the materials composing the product in terms of replenishment strategies.

The following UML sequence diagram shows the interaction of the SN agents over time (Figure 7). 


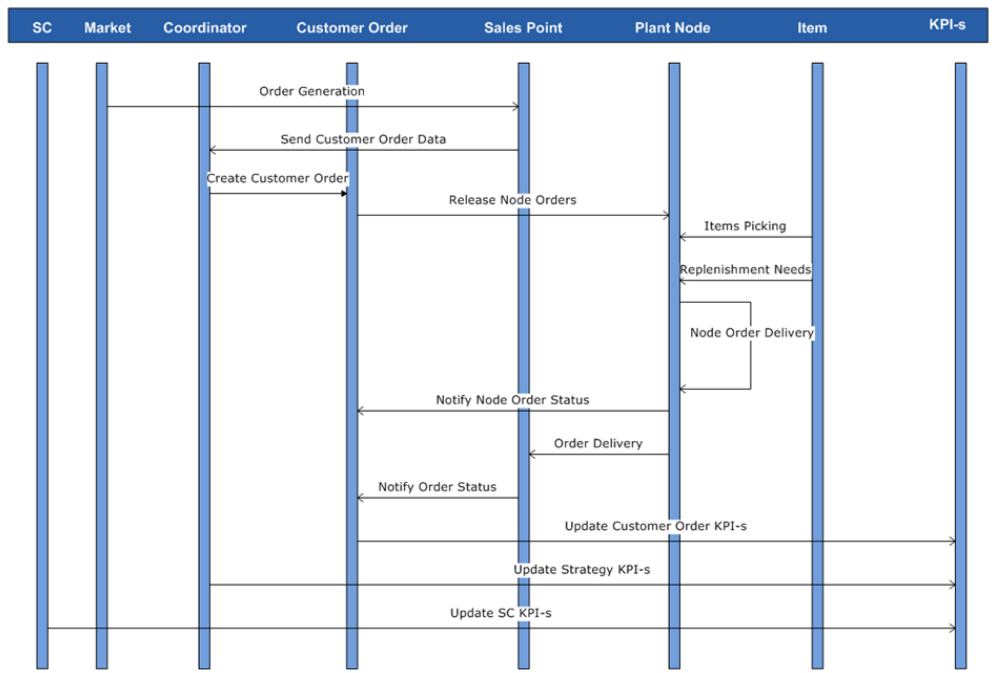

Figure 7. The DSS Sequence Diagram

The KPIs proposed for this case study are: (1) Order delivery time (the time periods (in day units) needed to serve the order to the customer); (2) Order cost (the total cost of manufacturing the order, its cost includes: purchasing cost; production cost; transportation cost; inventory cost; management cost); (3) Order profit (the profit generated with the order fulfilment); (4) Average SN delivery time (the average time periods in days needed by the SN to serve the set of orders); (5) Average SN workload (the ratio between the SN capacity used and the SN available capacity); (6) Average plant inventory cost (the average holding cost at the plant level); (7) Average plant workload (the ratio between the plant capacity used and the plant available capacity).

\subsection{Simulation interface}

The DSS has several interfaces and screens for the data entry/queries in the database, for the parameterization of optimization models, and also for the parameterization of simulations. To avoid making the paper too long, only the interface corresponding to the simulation runs is described. To visualize the simulations results, a user-friendly interface has been designed (see Figure 8). 


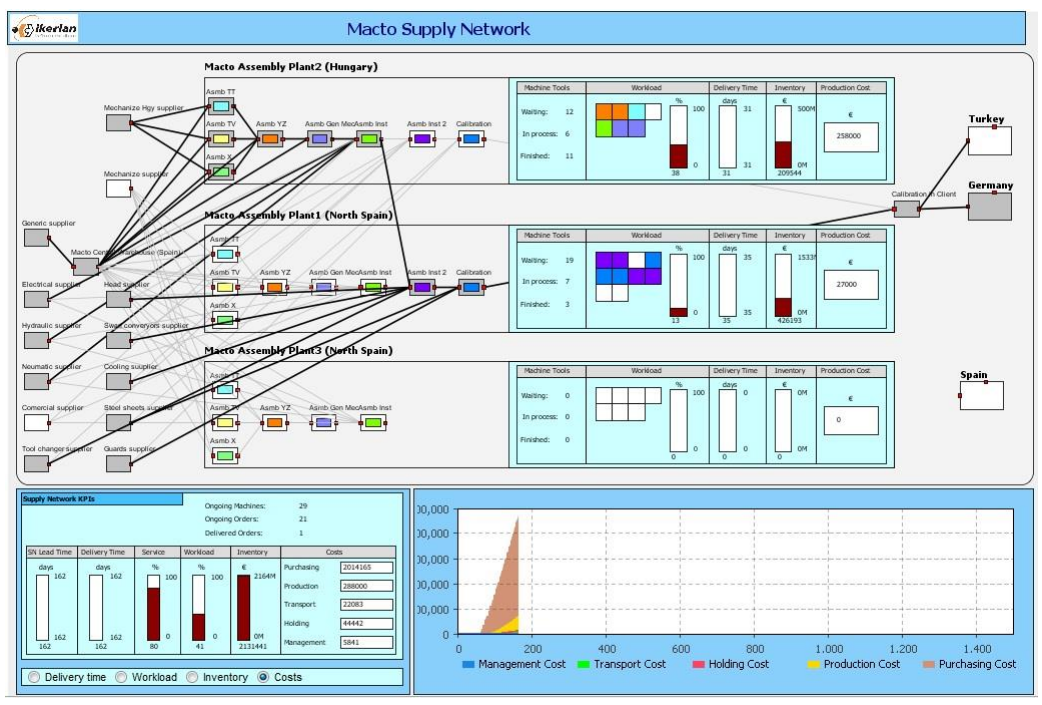

Figure 8: Screenshot of the Simulator Interface

In the simulation interface of the DSS, two main parts are observed: the SN configuration at the top; the different SN KPIs below.

At the top, the three plants considered in the set of orders are represented in the centre of the window. In each one, the different process activities are depicted with different coloured squares and their names. For each plant, the production indicators about the number of machines waiting, either in process or finished, are depicted. As a physical resource (available capacity) is no small concern, a graphical representation is used. The other indicators, e.g., workload, delivery time, holding and production costs, are also represented.

To the left of the plants that share all the information, a generic supplier of each component type is depicted. In this way, a generic supply base is represented (at least those involved in one of the set of orders) by squares, which do not provide all the details about the supplier involved. In addition, the three markets are represented on the right. The lines between the different $\mathrm{SN}$ members and processes are depicted to represent the flow of material and information. Lines appear in boldface when flows are activated in the $\mathrm{SN}$ instance, which is simulated. 
In Figure 8, the order is fulfilled using the components from the central warehouse in Spain and some local suppliers. The first assembly phase is performed in a Hungarian plant until the "Mec Asmb Inst" process is completed. The product is then transported to the Spanish plant, where the ultimate assembly and calibration processes are performed. Then the machine is sent to the German customer and is setup in the customer plant.

\section{Case study}

\subsection{Case study description}

The case study is about a Spanish company that designs and manufactures milling machines and milling centres in three assembly plants distributed in Europe. After the assembly and fine tuning phases, the machine is then transported to and installed in the customer plant. This company is composed of several European plants, managed in a distributed manner, and its supply base comprises some 40 suppliers with whom attempts are made to collaborate in planning tasks by sharing demand data, for example. Two plants are located in Spain and the third is situated in Hungary. The overall demand for milling machines in one year might exceed 80. Machines are sold principally in Europe (the major sales markets are Spain, Germany and Turkey), but Asia is a growing market.

Traditionally, the decision-making process is decentralized and leads to poor decisions for the SN. The new company strategy aims to create a synergy among plants via a collaborative planning tool for $\mathrm{SN}$ configuration and operations scheduling for all the SN members. Assembly operations for milling machines can be performed in any assembly plant, but costs differ among all three due to workforce costs, productivity and available capacity. Generally, the preliminary assembly stages are performed in 
Hungary because workforce costs are lower and the plant has its own local supplier network for cast-iron and machined parts. After finalizing the initial assembly, the halfassembled machines in Hungary are transported to Spain, where customization operations, careenage, fine tuning, tests and painting are performed. In the same plant, machine inspection and customer approval tasks are done before shipping to the final destination where the final in-house installation is done. Nevertheless, recently, operators were trained and are now able to perform the final assembly in Hungary, which helps reduce costs and enhances flexibility.

In this case study, the $\mathrm{SN}$ receives a new order for a milling machine from a German customer. The milling machine can be assembled and served using different SNCs or BOMs. Each plant has its supplier base to stock up with different associated lead times and costs, but there are distinct SNCs given the possibility of purchasing certain components from alternative suppliers, which offer a shorter delivery time, be it with extra charges. For example, the procurement time for the Horizontal Axis Cast ("H Axis Cast") is about 12 weeks and costs $€ 11,000$ for the Spanish plant and takes 12 weeks and costs $€ 7,500$ for the Hungarian plant. Moreover, suppliers cooperate with the assembly plants to offer the possibility of urgent transport with extra charges. Finally, there are alternative suppliers in both Spain and Hungary which offer a 10-week delivery date at a cost of $€ 14,000$ and $€ 10,000$, respectively.

Another alternative is to consider alternative BOMs. For example, the motorization set presents four possible variants and some can be substitutes for others. In this case, the customer requests specifications that imply the assembly of one variant, which has to be purchased. The delivery time for this component is quite long as this variant is a low-demand product. However according to the inventory data, another variant of the motorization set, a top component (in both technology and cost terms) can 
prove to be a compatible substitute component. This top component variant is available in both plants. The customer is not against upgrading if both the agreed delivery time and price of the machine are respected in the sales department.

In order to optimize its material flow, the assembly company offers certain flexibility to perform its transshipments. This flexibility, a common alternative in this industry, is to consider different ways of transporting a half-assembled machine between plants. To go about this, it is quite common to hire a single driver for normal transport. If necessary, the company can assume the consequent over-cost to hire two or more drivers to cut the delivery time.

The next subsection presents the complete solution data to calculate this order. The results and the KPIs values of each different solution for the given problem are discussed.

\subsection{Experiment results analysis}

Currently these two plants have 10 fixed orders that are either in process or planned to be assembled. The new order to be simulated is the eleventh. Once each member has introduced its data, the complete enumeration-based procedure finds 32 feasible solutions. Each solution is characterized by its SNC.

Table 2 lists each solution's characteristics. It is noteworthy that in practice, not all the solutions that the algorithm finds are simulated because those solutions with "poor estimated" benefits and "unsuitable estimated" delivery times are eliminated since they simulate only a limited quantity of solutions, particularly if the quantity of solutions substantially rises. In this case, the first (preliminary) and second (final) assembly phases can be performed in the two assembly plants (see the columns 1 and 2). In columns 3 and 4, the use of alternative suppliers and BOMs is presented, while column 5 characterizes the type of transshipment used. "Normal transshipment" is an 
operation that costs $€ 2,500$ and lasts 6 days, "Type 1 ” costs $€ 4,500$ and lasts 3 days, while "Type 2" costs $€ 6,250$ and lasts 2 days.

Table 2. Characteristics of the feasible solutions

\begin{tabular}{|c|c|c|c|c|c|}
\hline Solutions & Assembly phase 1 & Assembly phase 2 & $\begin{array}{c}\text { Use of alternative } \\
\text { supplier }\end{array}$ & $\begin{array}{c}\text { Use of alternative } \\
\text { BOM }\end{array}$ & $\begin{array}{c}\text { Type of } \\
\text { transshipment }\end{array}$ \\
\hline sol-1 & Plant2 & Plant2 & yes & no & No transshipment \\
\hline sol-2 & Plant2 & Plant2 & no & no & No transshipment \\
\hline sol-3 & Plant2 & Plant2 & yes & yes & No transshipment \\
\hline 501-4 & Plant2 & Plant2 & no & yes & No transshipment \\
\hline sol-5 & Plant1 & Plant1 & yes & no & No transshipment \\
\hline sol-6 & Plant1 & Plant1 & no & no & No transshipment \\
\hline sol-7 & Plant1 & Plant1 & yes & yes & No transshipment \\
\hline sol-8 & Plant1 & Plant1 & no & yes & No transshipment \\
\hline sol-9 & Plant2 & Plant1 & yes & no & Normal \\
\hline sol-10 & Plant2 & Plant1 & yes & no & Type1 \\
\hline sol-11 & Plant2 & Plant1 & yes & no & Type2 \\
\hline sol-12 & $\begin{array}{l}\text { Plant2 } \\
\end{array}$ & Plant1 & no & no & Normal \\
\hline sol-13 & Plant2 & Plant1 & no & no & Type1 \\
\hline sol-14 & Plant2 & Plant1 & no & no & Type2 \\
\hline sol-15 & Plant2 & Plant1 & yes & yes & Normal \\
\hline sol-16 & Plant2 & Plant1 & yes & yes & Type1 \\
\hline sol-17 & Plant2 & Plant1 & yes & yes & Type2 \\
\hline sol-18 & Plant2 & Plant1 & no & yes & Normal \\
\hline sol-19 & Plant2 & Plant1 & no & yes & Type1 \\
\hline sol-20 & Plant2 & Plant1 & no & yes & Type2 \\
\hline sol-21 & Plant1 & Plant2 & yes & no & Normal \\
\hline sol-22 & Plant1 & Plant2 & yes & no & Type1 \\
\hline 5ol-23 & Plant1 & Plant2 & yes & no & Type2 \\
\hline sol-24 & Plant1 & Plant2 & no & no & Normal \\
\hline sol-25 & Plant1 & Plant2 & no & no & Type1 \\
\hline sol-26 & Plant1 & Plant2 & no & no & Type2 \\
\hline sol-27 & Plant1 & Plant2 & yes & yes & Normal \\
\hline 5ol-28 & Plant1 & Plant2 & yes & yes & Type1 \\
\hline sol-29 & Plant1 & Plant2 & yes & yes & Type2 \\
\hline sol-30 & Plant1 & Plant2 & no & yes & Normal \\
\hline sol-31 & Plant1 & Plant2 & no & yes & Type1 \\
\hline 5ol-32 & Plant1 & Plant2 & no & yes & Type2 \\
\hline
\end{tabular}

Some data from one solution are provided in Tables 3, 4, 5, 6 and 7.

Table 3 lists the purchase strokes. Column 1 lists the name of the different purchase strokes, column 2 provides the associated SKUs, and column 3 associates the supplier of the transaction. Finally, the last three columns present the quantity of SKUs generated, and the cost to perform one purchase transaction along with its associated delivery time (or lead time). As observed, the named stroke is formed by the stroke type + SKU + supplier combination. Note that in this case, the SKU is unique and unitary for each purchase stroke.

Table 3. The purchase stroke table 


\begin{tabular}{|c|c|c|c|c|c|}
\hline Stroke & SKUOutput & Supplier & SKUOutput Quantity & Delivery Time (days) & Cost (euros) \\
\hline Purchase_Bed 01@Mechanized Supplier@Plant1 & Bed 01@Plant1 & Mechanized Supplier & 1 & 50 & 6625 \\
\hline Purchase_Guarding System@Guard Supplier Rum.@Plant2 & Guarding System@Plant2 & Guard Supplier Rum. & 1 & 40 & 8951 \\
\hline Purchase_H Axis Cast 01@Mechanized Supplier Alt.@Plant1 & H Axis Cast 01@Plant1 & Mechanized Supplier Alt. & 1 & 50 & 14000 \\
\hline Purchase_H Axis Commercial Kit 01@Central Warehouse@Plant1 & H Axis Commercial Kit 01@Plant1 & Central Warehouse & 1 & 50 & 6734 \\
\hline Purchase_H Axis Kit 01@Mechanized Supplier@Plant1 & H Axis Kit 01@Plant1 & Mechanized Supplier & 1 & 40 & 1250 \\
\hline Purchase_Head 01@Head Supplier@Plant2 & Head 01@Plant2 & Head Supplier & 1 & 40 & 26000 \\
\hline Purchase_Interface Module 01@Mechanized Supplier@Plant1 & Interface Module 01@Plant1 & Mechanized Supplier & 1 & 40 & 600 \\
\hline Purchase_Keypad 01@Guard Supplier@Plant1 & Keypad 01@Plant1 & Guard Supplier & 1 & 20 & 1200 \\
\hline Purchase_PED11_Cooling System@TTank Supplier@Plant2 & PED11_Cooling System@Plant2 & Tank Supplier & 1 & 20 & 7441 \\
\hline Purchase_PED11_Hydraulic Group@Hydr.Pneum. Supplier@Plant1 & PED11_Hydraulic Group@Plant1 & Hydr. Pneum. Supplier & 1 & 20 & 4651 \\
\hline Purchase_PED11_Pneumatic Group@Hydr.Pneum. Supplier@Plant1 & PED11_Pneumatic Group@Plant1 & Hydr. Pneum. Supplier & 1 & 20 & 1860 \\
\hline Purchase_PED11_Swarf Conveyor@Swarf Conveyors Supplier@Plant2 & PED11_Swarf Conveyor@Plant2 & Swarf Conveyors Supplier & 1 & 20 & 9301 \\
\hline Purchase_PED11_Turntable@Table Supplier@Plant2 & PED11_Turntable@Plant2 & Table Supplier & 1 & 50 & 44000 \\
\hline Purchase_PED11_Warehouse Adaptation@Tool Changer Supplier@Plant2 & PED11_Warehouse Adaptation@Plant2 & Tool Changer Supplier & 1 & 40 & 1000 \\
\hline Purchase Pulse X@Central Warehouse@Plant1 & PulseX@Plant1 & Central Warehouse & 1 & 15 & 0 \\
\hline Purchase_Pulse YZ@Central Warehouse@Plant1 & Pulse YZ@Plant1 & Central Warehouse & 1 & 15 & 0 \\
\hline Purchase_Tool Changer System 04@Tool Changer Supplier@Plant2 & Tool Changer System 04@Plant2 & Tool Changer Supplier & 1 & 40 & 4000 \\
\hline Purchase_Traverse Axis Cast 01@Mechanized Supplier@Plant1 & Traverse Axis Cast 01@Plant1 & Mechanized Supplier & 1 & 50 & 4000 \\
\hline Purchase Traverse Axis Commercial Kit 01@Central Warehouse@Plant1 & Traverse Axis Commercial Kit 01@Plant1 & Central Warehouse & 1 & 50 & 3805 \\
\hline Purchase_Traverse Axis Kit 01@Mechanized Supplier@Plant1 & Traverse Axis Kit 01@Plant1 & Mechanized Supplier & 1 & 40 & 1500 \\
\hline Purchase_Traverse Cover@Guard Supplier Rum.@Plant2 & Traverse Cover@Plant2 & Guard Supplier Rum. & 1 & 20 & 400 \\
\hline Purchase V Axis Cast A 01@Mechanized Supplier@Plant1 & V Axis Cast A 01@Plant1 & Mechanized Supplier & 1 & 50 & 8045 \\
\hline Purchase_VAxis Cast B $01 @$ Mechanized Supplier@Plant1 & V Axis Cast B $01 @$ Plant1 & Mechanized Supplier & 1 & 50 & 4000 \\
\hline Purchase_V Axis Commercial Kit 01@Central Warehouse@Plant1 & V Axis Commercial Kit $01 @$ Plant1 & Central Warehouse & 1 & 50 & 6169 \\
\hline Purchase_V Axis Kit 01@Mechanized Supplier@Plant1 & V Axis Kit 01@Plant1 & Mechanized Supplier & 1 & 40 & 1700 \\
\hline Purchase_Vertical Cover@Guard Supplier Rum.@Plant2 & Vertical Cover@Plant2 & Guard Supplier Rum. & 1 & - & 500 \\
\hline
\end{tabular}

Table 4 lists the transportation strokes for one solution. In this case, only two transportation strokes are considered. The first consists in transporting product "TA Inst Asmb" (the half-assembled machine) from "Plant1" to "Plant2". This operation takes 6 days and costs $€ 2,500$. The second stroke is the transportation of the finished product called "TA-A" from "Plant2" to the German customer plant location (3 days, €4,500).

Table 4. The transportation stroke table

\begin{tabular}{|c|c|c|c|c|c|c|}
\hline Stroke & SKUInput & SKUOutput Quantity & SKUOutput & SKUOutput Quantity & Transportation Time (days) & Cost (euros) \\
\hline Transport_PED11_TA Inst Asmb@Plant1_PED11_TA Inst Asmb@Plant2 & PED11_TA Inst Asmb@Plant1 & 1 & PED11_TA Inst Asmb@Plant2 & 1 & 6 & 2500 \\
\hline Transport_PED11_TA-A@Calibration R._PED11_TA-A@G.Customer & PED11_TA-A@Plant2 & 1 & PED11_TA-A@G.Customer & 1 & 3 & 4000 \\
\hline
\end{tabular}

Table 5 (respectively Table 6) presents the SKU outputs (the SKU inputs) for the transformation strokes. As observed, since all the transformation operations considered in this case study are of an assembly type, each transformation stroke has a unique and unitary SKU as the output. However the different SKUs in Table 6 are inputs for different strokes. For instance, stroke "Transformation_PED11_TA Inst 2 Asmb@Plant2" consumes one unit of the following SKUs, when one stroke unit is performed: “Head 01@Plant2”, “PED11_Cooling System@Plant2”, “PED11_Swarf Conveyor@Plant2”, “PED11_TA Inst Asmb@Plant2”, “PED11_Turntable@Plant2”, “PED11_Warehouse Adaptation@Plant2” and “Tool Changer System 04@Plant2”. Table 7 presents the different KPIs values of the simulation runs. In this case, the order cost and profit for order 11 are necessary because, in some cases, the sales 
price can change depending on the BOMs. For example in solution 16, the profit is not that high because one component is unsuitable for the customer and a discount has to be offered.

Table 5. SKU output of the transformation stroke

\begin{tabular}{|c|c|c|c|c|}
\hline Stroke & SKUOutput & SKUOutput Quantity & $\begin{array}{l}\text { y Operation time (days) } \\
\end{array}$ & Cost (euros) \\
\hline Transformation_PED11_TA Inst 2 Asmb@Plant2 & PED11_TA Inst 2 Asmb@Plant2 & 1 & 3 & 1400 \\
\hline Transformation_PED11_TA Inst Asmb@Plant1 & PED11_TA Inst Asmb@Plant1 & 1 & 13 & 1900 \\
\hline Transformation_PED11_TA Mechanical Asmb@Plant1 & PED11_TA Mechanical Asmb@Plant1 & 1 & 3 & 600 \\
\hline Transformation_PED11_TA-A@Plant2 & PED11_TA-A@Plant2 & 1 & 3 & 5211 \\
\hline Transformation_PED11_TAA@Plant2 & PED11_TAA@Plant2 & 1 & 13 & 3500 \\
\hline Transformation_PED11_X Module@Plant1 & PED11_X Module@Plant1 & 1 & 3 & 600 \\
\hline Transformation_PED11_YZ Module@Plant1 & PED11_YZ Module@Plant1 & 1 & 8 & 1272 \\
\hline
\end{tabular}

Table 6. SKU input of the transformation stroke

\begin{tabular}{|c|c|c|}
\hline Stroke & SKUInput & SKUInput Quantity \\
\hline Transformation_PED11_TA Inst 2 Asmb@Plant2 & Head 01@Plant2 & 1 \\
\hline Transformation_PED11_TA Inst 2 Asmb@Plant2 & PED11_Cooling System@Plant2 & 1 \\
\hline Transformation_PED11_TA Inst 2 Asmb@Plant2 & PED11_Swarf Conveyor@Plant2 & 1 \\
\hline Transformation_PED11_TA Inst 2 Asmb@Plant2 & PED11_TA Inst Asmb@Plant2 & 1 \\
\hline Transformation_PED11_TA Inst 2 Asmb@Plant2 & PED11_Turntable@Plant2 & 1 \\
\hline Transformation_PED11_TA Inst 2 Asmb@Plant2 & PED11_Warehouse Adaptation@Plant2 & 1 \\
\hline Transformation_PED11_TA Inst 2 Asmb@Plant2 & Tool Changer System 04@Plant2 & 1 \\
\hline Transformation_PED11_TA Inst Asmb@Plant1 & PED11_Hydraulic Group@Plant1 & 1 \\
\hline Transformation_PED11_TA Inst Asmb@Plant1 & PED11_Pneumatic Group@Plant1 & 1 \\
\hline Transformation_PED11_TA Inst Asmb@Plant1 & PED11_TA Mechanical Asmb@Plant1 & 1 \\
\hline Transformation_PED11_TA Mechanical Asmb@Plant1 & Bed 01@Plant1 & 1 \\
\hline Transformation_PED11_TA Mechanical Asmb@Plant1 & Interface Module 01@Plant1 & 1 \\
\hline Transformation_PED11_TA Mechanical Asmb@Plant1 & Keypad 01@Plant1 & 1 \\
\hline Transformation_PED11_TA Mechanical Asmb@Plant1 & Motorization Kit 04@Plant1 & 1 \\
\hline Transformation_PED11_TA Mechanical Asmb@Plant1 & PED11_X Module@Plant1 & 1 \\
\hline Transformation_PED11_TA Mechanical Asmb@Plant1 & PED11_YZ Module@Plant1 & 1 \\
\hline Transformation_PED11_TA-A@Plant2 & PED11_TAA@Plant2 & 1 \\
\hline Transformation_PED11_TAA@Plant2 & Guarding System@Plant2 & 1 \\
\hline Transformation_PED11_TAA@Plant2 & PED11_TA Inst 2 Asmb@Plant2 & 1 \\
\hline Transformation_PED11_TAA@Plant2 & Traverse Cover@Plant2 & 1 \\
\hline Transformation_PED11_TAA@Plant2 & Vertical Cover@Plant2 & 1 \\
\hline Transformation_PED11_X Module@Plant1 & H Axis Cast 01@Plant1 & 1 \\
\hline Transformation_PED11_X Module@Plant1 & H Axis Commercial Kit 01@Plant1 & 1 \\
\hline Transformation_PED11_X Module@Plant1 & H Axis Kit 01@Plant1 & 1 \\
\hline Transformation_PED11_X Module@Plant1 & Pulse X@Plant1 & 1 \\
\hline Transformation_PED11_YZ Module@Plant1 & Pulse YZ@Plant1 & 1 \\
\hline Transformation_PED11_YZ Module@Plant1 & Traverse Axis Cast 01@Plant1 & 1 \\
\hline Transformation_PED11_YZModule@Plant1 & Traverse Axis Commercial Kit 01@Plant1 & 1 \\
\hline Transformation PED11_YZ Module@Plant1 & Traverse Axis Kit 01@Plant1 & 1 \\
\hline Transformation_PED11_YZ Module@Plant1 & V Axis Cast A 01@Plant1 & 1 \\
\hline Transformation_PED11_YZ Module@Plant1 & V Axis Cast B $01 @$ Plant1 & 1 \\
\hline ant1 & V Axis Commercial Kit 01@Plant1 & 1 \\
\hline Transformation_PED11_YZModule@Plant1 & V Axis Kit 01@Plant1 & 1 \\
\hline
\end{tabular}

Figure 9 represents the value of the order delivery time and the order profit for each solution. Figure 10 depicts the values of the SN, "Plant1" and "Plant2" workload.

This simulation experiment allows the central decision maker to discover the impact on the value of the different KPIs for each alternative solution. When comparing the simulation results, the difference between each solution of the set is significant: A 28-day delivery time between solution 32 (117 days) and solution 9 (145 days); A profit of $€ 24,398$ between solution 1 and solution $8 ; 19.8 \%$ in the workload value between the plants in solution 6 and solution 15 .

Table 7. Experimental results 


\begin{tabular}{|c|c|c|c|c|c|c|c|c|c|}
\hline \multirow[b]{2}{*}{ Solutions } & \multicolumn{3}{|c|}{ KPIs for Order 11} & \multicolumn{2}{|c|}{ KPIs for Supply Network } & \multicolumn{2}{|c|}{ KPIs for Plant1 } & \multicolumn{2}{|c|}{ KPIs for Plant2 } \\
\hline & \begin{tabular}{|c} 
Delivery Time \\
(days)
\end{tabular} & \begin{tabular}{|c|}
$\begin{array}{c}\text { Order cost } \\
\text { (euros) }\end{array}$ \\
\end{tabular} & $\begin{array}{c}\begin{array}{c}\text { Profit } \\
\text { (euros) }\end{array} \\
\end{array}$ & $\begin{array}{c}\text { Average Delivery } \\
\text { Time (dias) }\end{array}$ & \begin{tabular}{|c|}
$\begin{array}{c}\text { Workload } \\
(\%)\end{array}$ \\
\end{tabular} & \begin{tabular}{|c} 
Workload \\
$(\%)$
\end{tabular} & \begin{tabular}{|c|} 
Total Inventory \\
cost (euros)
\end{tabular} & \begin{tabular}{|c|}
$\begin{array}{c}\text { Workload } \\
(\%)\end{array}$ \\
\end{tabular} & $\begin{array}{c}\text { Total Inventory } \\
\text { cost (euros) }\end{array}$ \\
\hline sol-1 & 136 & 179254 & 22746 & 141 & 79.2 & 72.6 & 405135 & 85.8 & 252939 \\
\hline sol-2 & 136 & 181754 & 20246 & 141 & 79.2 & 72.6 & 405135 & 85.8 & 254386 \\
\hline sol-3 & 130 & 179986 & 22014 & 141 & 79.2 & 72.6 & 405135 & 82.5 & 247436 \\
\hline sol-4 & 121 & 182486 & 19514 & 140 & 75.9 & 72.6 & 405135 & 82.5 & 242148 \\
\hline sol-5 & 133 & 199120.75 & 2879.25 & 141 & 82.5 & 92.4 & 459209 & 72.6 & 200217 \\
\hline sol-6 & 133 & 202120.75 & -120.75 & 141 & 82.5 & 92.4 & 461073 & 72.6 & 200217 \\
\hline sol-7 & 133 & 200652.75 & 1347.25 & 141 & 82.5 & 92.4 & 458083 & 72.6 & 200217 \\
\hline sol-8 & 118 & 203652.75 & -1652.75 & 140 & 79.2 & 85.8 & 447592 & 72.6 & 200217 \\
\hline sol-9 & 145 & 191191.75 & 10808.25 & 142 & 79.2 & 79.2 & 450633 & 82.5 & 212012 \\
\hline sol-10 & 142 & 193191.75 & 8808.25 & 142 & 79.2 & 79.2 & 449194 & 82.5 & 212012 \\
\hline sol-11 & 141 & 194941.75 & 7058.25 & 142 & 79.2 & 79.2 & 448714 & 82.5 & 212012 \\
\hline sol-12 & 145 & 193691.75 & 8308.25 & 142 & 79.2 & 79.2 & 450837 & 82.5 & 213256 \\
\hline sol-13 & 142 & 195691.75 & 6308.25 & 142 & 79.2 & 79.2 & 449397 & 82.5 & 213256 \\
\hline sol-14 & 141 & \begin{tabular}{|l|}
197441.75 \\
\end{tabular} & 4558.25 & 142 & 79.2 & 79.2 & 448917 & 82.5 & 213256 \\
\hline sol-15 & 139 & \begin{tabular}{|l|}
191923.75 \\
\end{tabular} & 10076.25 & 142 & 79.2 & 79.2 & 447227 & 79.2 & 209795 \\
\hline sol-16 & 136 & \begin{tabular}{|l|}
193923.75 \\
\end{tabular} & \begin{tabular}{|l|}
807.25 \\
\end{tabular} & 141 & 79.2 & 79.2 & 445788 & 79.2 & 209795 \\
\hline sol-17 & 135 & \begin{tabular}{|l|}
195673.75 \\
\end{tabular} & 6326.25 & 141 & 79.2 & 79.2 & 445308 & 79.2 & 209795 \\
\hline sol-18 & 130 & 194423.75 & 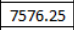 & 141 & 79.2 & 79.2 & 443113 & 79.2 & 208441 \\
\hline sol-19 & 127 & \begin{tabular}{|l|}
196423.75 \\
\end{tabular} & 5576.25 & 140 & 79.2 & 79.2 & 441673 & 79.2 & 208441 \\
\hline sol-20 & 126 & 198173.75 & \begin{tabular}{|l|}
3826.25 \\
\end{tabular} & 140 & 79.2 & 79.2 & 441194 & 79.2 & 208441 \\
\hline sol-21 & 136 & 192183 & 9817 & 141 & 82.5 & 85.8 & 418315 & 75.9 & 242298 \\
\hline sol-22 & 133 & 194183 & 7817 & 141 & 79.2 & 85.8 & 418315 & 75.9 & 240918 \\
\hline sol-23 & 132 & 195933 & 6067 & 141 & 82.5 & 85.8 & 418315 & 75.9 & 240458 \\
\hline sol-24 & 136 & 195183 & 6817 & 141 & 82.5 & 85.8 & 419935 & 75.9 & 242542 \\
\hline sol-25 & 133 & 197183 & 4817 & 141 & 79.2 & 85.8 & 419935 & 75.9 & 241163 \\
\hline sol-26 & 132 & 198933 & 3067 & 141 & 82.5 & 85.8 & 419935 & 75.9 & 240703 \\
\hline sol-27 & 136 & 193715 & 8285 & 141 & 82.5 & 85.8 & 417716 & 75.9 & 241771 \\
\hline sol-28 & 133 & 195715 & 6285 & 141 & 79.2 & 85.8 & 417716 & 75.9 & 240391 \\
\hline sol-29 & 132 & 197465 & 4535 & 141 & 82.5 & 85.8 & 417716 & 75.9 & 239932 \\
\hline sol-30 & 121 & 196715 & 5285 & 140 & 79.2 & 82.5 & 414177 & 75.9 & 235120 \\
\hline sol-31 & 118 & 198715 & 3285 & 140 & 79.2 & 82.5 & 414177 & 75.9 & 233740 \\
\hline sol-32 & 117 & 200465 & 1535 & 140 & 79.2 & 82.5 & 414177 & 75.9 & 233281 \\
\hline
\end{tabular}

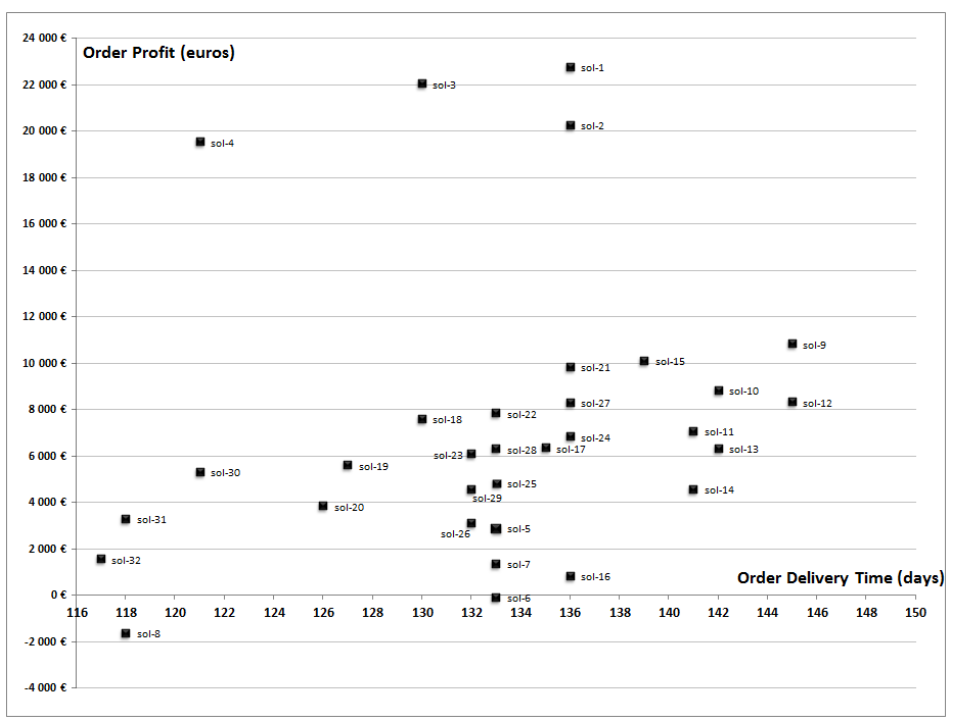

Figure 9: Order delivery time and order profit for each simulation run

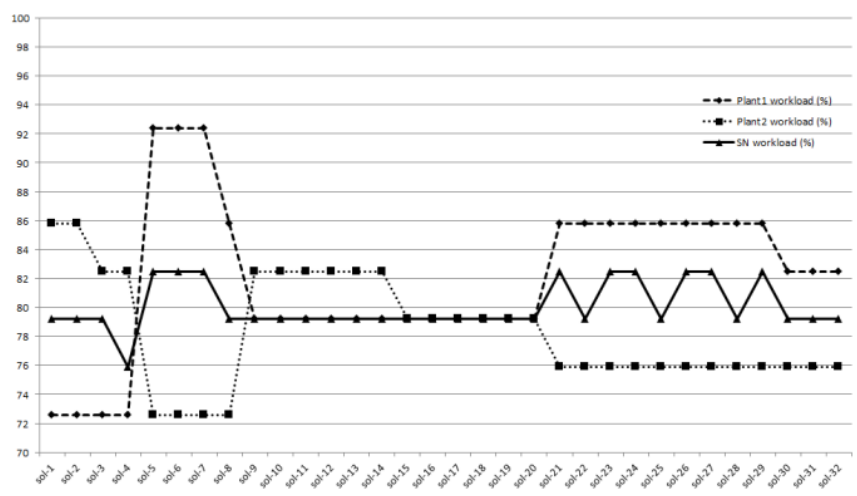

Figure 10: Workload results 
As the customer requires the milling machine before 132 days, the acceptable solutions are: $3,4,8,18,19,20,23,26,29,30,31,32$. In terms of profits, solution 8 has to be ruled out because it implies a loss. Solutions 3 and 4 imply high profits, and solutions 18, 19, 23 and 30 imply medium profits. In terms of the workload between both plants, solutions 18,19 and 20 imply a workload that is totally levelled between the two plants. However, solution 4 assumes a minimum SN workload with $75.9 \%$. So a good solution that "satisfices" both the customer and the central decision maker is solution 3 or solution 4 . Solution 4 has been chosen because: its profit is the second most important of the set of solutions ( $€ 2,500$ less than solution 3$)$; its delivery time is 121 days and it respects the due date fixed by the customer. It also takes 9 days less than the delivery time for Solution 3; the SN workload is the lowest of the set of solutions. Solution 3 gives the highest profit, but solution 4 implies a lower SN workload.

\subsection{Managerial implications}

At a practical level, some managerial implications for industries can be addressed. Relevant improvements in the SN after implementation have been detected:

- As the tool is increasingly used, users' implicit knowledge is being incorporated into the databases. This allows increasingly more alternative operations to be contemplated, which provide the central decision maker with a solution that "satisfices" all the SN members.

- As it allows the relevant KPIs for the SN as a whole to be considered, the SN can accept more tailor-made orders and offers more reliable delivery dates.

- Being able to visualize the simulation of the obtained results has helped increase the collaboration among the various $\mathrm{SN}$ members. 
- The need to consider and evaluate all the operations implies greater concern about the need to enhance the quality of the data included in the various information systems.

A greater understanding of how the $\mathrm{SN}$ behaves when allocating the different operations to be executed in each order among the various SN members.

\section{Conclusions}

This paper describes a DSS to solve the supply network configuration and the operations scheduling problems for the machine tool industry. A novel relational database structure that is capable of considering alternative operations (purchasing, production and transport) and alternative BOMs (upgrading, reconfiguring custom products) has been introduced and the steps of an algorithm for complete enumeration to determine all the feasible solutions have been presented. Given the problem's multicriteria nature, the various feasible solutions are evaluated in a simulator based on multiagent technology. The simulator evaluates different KPIs relating not only to the order itself, but also to the SN.

Some experimental results for a Spanish company, which assembles highly customized machine tools in several European plants and receives a specific order, are presented. A solution that "satisfices" all the SN members is found and is based on real data. The solution chosen by the decision maker is that which takes into account the criteria of both the order (the delivery date of the order and its profit) and the SN (the workload levels and flexibility capacity for incoming orders).

As future research lines, it would be interesting to consider re-scheduling older orders to find better solutions for the $\mathrm{SN}$ as it can be considered the main limitation of the tool. It would also be fitting to design and propose algorithms that transform the data in existing conventional ERPs into those used in the DSS so that they are capable 
of using the stroke concept. Another future research line would consist in incorporating variants such as uncertainty (stochastic or by fuzzy methods).

\section{Acknowledgements}

We thank the EWG-DSS and their four expert anonymous referees as well as the guest editorial board for their useful suggestions and criticism on earlier versions of this paper. The research leading to these results has received funding from the European Community's Seventh Framework Programme (FP7/2007-2013) under grant agreement no. NMP2-SL-2009- 229333 and has been partially supported by the Spanish Ministry of Science and Innovation within the "Proyectos de Investigación Fundamental No Orientada Programme through Project "CORSARI MAGIC DPI2010-18243". Julien Maheut holds a VALi+d grant funded by the Regional Valencian Government (Ref. ACIF/2010/222).

\section{References}

Aissaoui,N., Haouari, M., and Hassini, E., 2007. Supplier Selection and order lot sizing modeling: a review. Computers \& Operations Research, 34 (12), 3516-3540.

Aydin,A.O. and Güngör, A. 2005. Effective relational database approach to represent bills-of-materials. International Journal of Production Research, 43 (6), 11431170.

Baptiste, P., Alsène, É., and Gaudimier, R. 2008. Integration of production and shipping planning: a co-operative approach. Production Planning \& Control, 19 (7), 645654.

Chaabane, A., Ramudhin, A., and Paquet, M., 2011. Designing supply chains with sustainability considerations. Production Planning \& Control, 22 (8), 727-741.

Chow, W., 1991. An optimal product-reconfiguration policy due to order changes. Production Planning \& Control, 2 (1), 52-58.

Christopher, M., 1998. Logistics and Supply Chain Management - Strategies for 
reducing cost and improving service, 2nd Edition.

Cowling,P., 2003. A flexible decision support system for steel hot rolling mill scheduling. Computers \& Industrial Engineering, 45 (2), 307-321.

Da Silveira,G., Borenstein, D., and Fogliatto, F.S., 2001. Mass customization: Literature review and research directions. International Journal of Production Economics, $72(1), 1-13$.

Farrell, R.R. and Maness, T.C., 2005. A relational database approach to a linear programming-based decision support system for production planning in secondary wood product manufacturing. Decision Support Systems, 40 (2), 183196.

Garcia-Sabater, J.P., Maheut, J., and Garcia-Sabater, J.J., 2012. A two-stage sequential planning scheme for integrated operations planning and scheduling system using MILP: the case of an engine assembler. Flexible Services and Manufacturing Journal, 24 (7), 171-209.

Garcia-Sabater, J.P., Maheut, J., and Marin-Garcia, J.A., 2013. A new formulation technique to model Materials and Operations Planning: the Generic Materials and Operations Planning (GMOP) Problem. European J.Industrial Engineering, $7(2), 119-147$.

Gomes da Silva, C., Figueira, J., Lisboa, J., and Barman, S., 2006. An interactive decision support system for an aggregate production planning model based on multiple criteria mixed integer linear programming. Omega, 34 (2), 167-177.

Graves, S.C. and Willems, S.P., 2005. Optimizing the supply chain configuration for 
new products. Management Science, 51 (8), 1165-1180.

Guinery, J. and MacCarthy, B., 2009. Managing key interfaces in production planning and control. Production Planning \& Control, 20 (1), 40-56.

Hernández, J.E., Alemany, M.M.E., Lario F.C., and Poler, R., 2009. SCAMM-CPA: A supply chain agent-based modelling methodology that supports a collaborative planning process. Innovar, 34 (19), 99-120.

Karpov, Y.G., Ivanovski, R.I., Voropai, N.I., and Popov, D.B., 2005. Hierarchical modeling of electric power system expansion by anylogic simulation software. In Power Tech, 2005 IEEE Russia, 1-5.

Maheut, J. and Garcia-Sabater, J.P., 2011. La Matriz de Operaciones y Materiales y la Matriz de Operaciones y Recursos, un nuevo enfoque para resolver el problema GMOP basado en el concepto del Stroke. Dirección y Organización, 45 (1), 4657.

Maheut, J. and Garcia-Sabater, J.P., 2013. Algorithm for complete enumeration based on a stroke graph to solve the supply network configuration and operations scheduling problem. Journal of Industrial Engineering and Management, 6 (2) In press, doi:10.3926/jiem.550.

Maheut, J., Garcia-Sabater, J.P., and Mula, J., 2012. A supply Chain Operations LotSizing and Scheduling Model with Alternative Operations. In S.P. Sethi, M. Bogataj, and L. Ros-McDonnell Editors, Industrial Engineering: Innovative Networks. London: Springer-Verlag London, 309-316.

Mula,J., Maheut, J., and Garcia-Sabater, J. P., 2012. Supply Chain Network Design. 
Journal of Marketing and Operations Management Research, 1 (2), 378-383.

Power, D.J. and Sharda, R., 2009. Decision Support Systems. In S.Y. Nof Editor, Springer Handbook of Automation . Springer Berlin Heidelberg, 1539-1548.

Ram, B., Naghshineh-Pour, M.R., and Xuefeng, Y., 2006. Material requirements planning with flexible bills-of-material. International Journal of Production Research, 44 (2), 399-415.

Respicio, A., Captivo, M.E., and Rodrigues, A.J., 2002. A DSS for production planning and scheduling in the paper industry. In Decision Making and decision support in the internet age - Proceedings of the DSIAge2002, 298-308.

Saiz, E., Castellano, E., Uribetxebarria, J., and Besga, J.M., 2012. Criterios para la asignación de estrategias de cumplimentación de pedidos en el sector de bienes de equipo: aplicación a un fabricante de máquina-herramienta. Dyna, 87 (3), 316-325.

Saiz, E., Castellano, E., Besga, J.M., and Uribetxeberria, J., 2009. Customized Order Fulfillment in a Machine Tool Supply Network. In MCPC 2009: The World Conference on Mass Customization and Personalization, 1-13.

Stadtler, H., 2005. Supply chain management and advanced planning--basics, overview and challenges. European Journal of Operational Research, 163 (3), 575-588.

Stadtler, H., 2009. A framework for collaborative planning and state-of-the-art. $O R$ Spectrum, 31, 5-30. 
Tynjälä, T. and Eloranta, E., 2007. Investigating the effect of product variants, and demand distributions on the optimal demand supply network setup. Production Planning \& Control, 18 (7), 561-572. 